\title{
DYNAMIC STOP LIST FOR THE GUJARATI LANGUAGE USING RULE BASED APPROACH
}

\author{
Mr. Chandrakant D. Patel \\ Dr. Jayeshkumar M. Patel
}

\begin{abstract}
:
Text classification, document cluster, and similar endeavors area unit important analysis spaces underpinning a large vary of problems and applications within the area of internet intelligence. A typical approach, once cluster or otherwise classifying documents algorithmically, is to represent an online document as a vector of numbers derived from the frequencies of words therein document, wherever the words area unit taken from the complete assortment of documents into consideration. A tried approach is to use an inventory of "stop" words (also known as a 'stop list'), that establish frequent words like 'and' and 'or' which might be unlikely to Words within the stop list area unit thus not enclosed within the vector that represents a document. Current stop lists area unit arguably noncurrent within the lightweight of fluctuations in word usage, and conjointly arguably innocent of sure candidate generic stop lists, thus delivery into question that we tend to explore this by developing new stop lists in an exceedingly rule based method.
\end{abstract}

Keywords: Rule based, Diacritics, Preprocessing step, Accuracy Evaluation

\section{Introduction:}

This is a 21 st century which is called as Information century. Every day massive sites will open and added web page with plenty of information in several types. For Example: written data, natural language text, spoken languages, sounds and various multimedia information including audio and video. Text is a universal method to convey information and communication. However, text can be easily processed and less expensive than other media types.[1], [2]

There is surprisingly very little work on stop words extraction available in the literature [3]. In Information Retrieval (IR), the goal is to discard the stop words and concentrate the analysis on the more informative words [4], [5]. It is common practice to remove common functional words is called as stop words. In English, "the", "it"," but", "and" etc... are all consider as stop words because its expose nothing for the particular statement. So, such terms need to remove to improve the index of document and save time for execution for searching the document in the directory. However, there are a great number of non-informative words, such as articles, prepositions and conjunctions called as stop words. The stop words list is language and task dependent. So, a set of general words can be considered as stop words for the almost all tasks such as and and or in the English language. A stop word may be identified as a word that has the same likelihood of occurring in those documents not relevant to a query as in those documents relevant to the query [6].

The common words or stop words which is commonly used in every language. The stop words are needed to care when we are focusing on important words in text mining 
Towards Excellence: An Indexed, Refereed \& Peer Reviewed Journal of Higher Education / Mr.

Chandrakant Patel \& Dr. Jayeshkumar Patel / Page 594-607

application. Example: In search engine, if query is "Who is Dr. Abdul Kalam?" and search engine start searching on every tokens then it will retrieve a lot of pages with including terms such as "who", "is", "Dr.", "Abdul" and "Kalam?". After the Stop words remove the given query then search engine will focus on important words such as "Abdul", "Kalam?" that is the optimum result for the information retrieve and increase the performance of searching. The stop words will help us to prevent being index words for Information Retrieval System (IRS).[7] The stop words can be categories as domain and generic stop words. The domain words of education corpus different from clinical corpus. So, it is depends on domain area which use by the user or search engine or corpus. The generic stop words are independent from domain and it is common to all kinds of corpus or language.

\section{Figure 1 Category of Stop Lists}

The eliminations of stop words in Gujarati text documents contribute to a significant amount of increase in precision values in IRS.[8] The characteristics of the stop words [9], [10] are...

- Stop words are most frequently occurs.

- They are not useful indicator for the content.

- They are representing as syntactic rather than semantic role.

- Stop words are often used to connect different parts of sentence.

- After remove stop words, the accuracy of retrieval won't be affected.

\section{Literature review on Stop words:}

W John Wilbur et. al. [6] have been taken to identified automatically English language stop words based on statistical approach with vector retrieval methodology based on cosine coefficient of document-document similarity. It is possible to find the stop words from the collection using statistical approach. This algorithm implemented and tested on large MEDLINE corpus which is subset of bio-technology and able to identified up to $75 \%$ stop words and achieved to identify up to 310 stop words. Tin Kam Ho et. al. [4] have been taken to fast identification of stop words using font learning and keyword spotting based on statistical method. The algorithm implemented using the fast locating procedure and statistics of the individual words with immediate neighbor and tested on 400 page images and able to identified $63 \%$ stop words with maximum no. of stop words 146 obtained from set J out of three sets. Catarina Silva et. al. [11] have been taken issue to resolve three major preprocessing steps were evaluated, namely the removal of words with low document frequency, the filtering the words in a stop word list and the use of stemming. The algorithm performed based on eight conditions and validation measure through precision, recall and F1. The papers was concluded that the most significant of them was the stop words removal, whose influence was determinant and worthy of more research. Mark P Sinka et. al. [12] have been taken to generate web specific stop list using web based analysis task. The algorithm used entropy analysis which was derived from Van Rijsbergen's methods and evaluating and compared the performance using K-means algorithm. Feng Zou et. al. [13] have been taken to construct the list of the Chinese stop words using automatic aggregated methodology based on statistical and information models. The algorithm was implemented on Chinese language and compares the stop words list with English language. Stop words are extracted from TREC-5 and TREC-6 corpora which are widely accepted as standard corpora for Chinese processing. Lili Hao et. al.[10] have been taken to automatic identification of stop words in the Chinese language using statistical correlation based on the weighted Chi-square. The algorithm was implemented and tested on real world Chinese corpus of the Mayor's Public Access Line Project texts and which can speed up the calculation and increase the accuracy of classification at the same time. Gong Zheng et. al. [9] have been taken to selection method of Mongolian stop words based on statistical method. The algorithm was combined with Parts 
Towards Excellence: An Indexed, Refereed \& Peer Reviewed Journal of Higher Education / Mr.

Chandrakant Patel \& Dr. Jayeshkumar Patel / Page 594-607

Of Speech (POS) based Mongolian features and result was improved than the simply get the stop words from statistical methods. Zhou Yao et. al. [5] have been taken to summarized definition, methods of extraction and different filter methods to construct stop words. The algorithm was implemented with three different methods such as Sequence filter, MRU filter and Hash filter to access and store the stop words in Chinese language. These algorithms were comparing with efficiency and proved that hash filter method was the fastest with mentioned with following aspects:

- The accuracy of text mining should not be decreased if the stop-words were deleted.

- The dimensionality of the text feature space should be reduced if the stop-words were deleted.

Hakan Ayral et. al.[14] have been taken to prepared automatic method for domain specific stop words. The algorithm was implemented based on Bayesian classifier using posteriori probability estimation. The output of the algorithm was compared with English language stop word list with the help of PASCAL and Oxford English corpus. A N K Zaman et. al. [15] have been taken to evaluate stop words based on Latent Sematic Indexing (LSI). The algorithm was implemented and tested on TREC-8 using evaluation parameters and concluded that the stop words lists improved retrieval performance. Laurie Butgereit et. al. [14] have been taken to list out the domain stop words for the "Dr Math" project in the South Africa of mathematics subject. This algorithm implemented and tested on MXit conversions between "Dr Math" and pupils during the 2010 academic year. Hardik Joshi et. al. [16] have been taken into experiment on stop word elimination on Gujarati documents. The algorithm was implemented and tested on FIRE corpus using MAP (Mean Average Precision) which metric used to measure efficiency of IR tasks and concluded that elimination of stop-words in Gujarati text documents contribute to a significant amount of increase in precision values in IR task. Satyendr Singh et. al.[17] have been taken to identify stop words using context window mechanism on Hindi Word Sense Disambiguation. The algorithm was implemented and tested on manually created corpus and evaluated using precision and recall. Patcharanut Daowadung et. al. [18] have been taken to construct Thai stop word list and evaluate the impact of eliminating stop word on readability assessment of Thai text. This algorithm was implemented and tested in 1,188 textbook articles used by students from grade 1 to grade 6 with pre-processing steps such as Word Segmentation, Stop word list extraction and features selection based on TF-IDF. Vandana Jha et. al [19] have been taken to implemented for Hindi language which was based on DFA. This algorithm implemented and tested with TREC corpus with pattern matching method and concluded with promising result in same environment. Rajnish M. Rakholia et. al. [20] have been taken to rule based approach to collect an automatic and dynamic stop words for the Gujarati language. The algorithm was implemented and tested on manually generated corpus and got the average accuracy with $98.10 \%$ and $94.08 \%$ respectively.

Table 1 Comparison study for Stop Words

\begin{tabular}{|l|l|l|l|l|l|l|}
\hline Sr. & Language & $\begin{array}{l}\text { Number of } \\
\text { Identified } \\
\text { Stop Words }\end{array}$ & Approach & Corpus & Reference Paper & Year \\
\hline
\end{tabular}


Towards Excellence: An Indexed, Refereed \& Peer Reviewed Journal of Higher Education / Mr.

Chandrakant Patel \& Dr. Jayeshkumar Patel / Page 594-607

\begin{tabular}{|c|c|c|c|c|c|c|}
\hline 1 & English & 310 & Statistical & Medline & W John Wilbur et. al. [6] & 1992 \\
\hline 2 & English & 146 & Word shapes & Manually & Tin Kam Ho et. al. [4] & 1999 \\
\hline 3 & English & - & $\begin{array}{l}\text { Super Vector } \\
\text { Machine }\end{array}$ & $\begin{array}{l}\text { Reuters } \\
21578\end{array}$ & Catarina Silva et. al. [11] & 2003 \\
\hline 4 & English & - & Entropy & $\begin{array}{l}\text { Bank } \\
\text { Search }\end{array}$ & Mark P Sinka et. al. [12] & 2003 \\
\hline 5 & Chinese & - & Statistical & $\begin{array}{l}\text { TREC-5, } \\
\text { TREC-6 }\end{array}$ & Feng Zou et. al. [13] & 2006 \\
\hline 6 & Chinese & 500 & Statistical & $\begin{array}{l}\text { Public } \\
\text { Access } \\
\text { texts }\end{array}$ & Lili Hao et. al.[10] & 2008 \\
\hline 7 & Mongolian & - & Statistical & TREC & Gong Zheng et. al. [9] & 2010 \\
\hline 8 & Chinese & - & $\begin{array}{l}\text { Sequence, } \\
\text { MRU, Hash }\end{array}$ & $\begin{array}{l}\text { FUDAN } \\
\text { University } \\
\text { Corpus }\end{array}$ & Zhou Yao et. al. [5] & 2011 \\
\hline 9 & English & - & Bayesian & $\begin{array}{l}\text { PASCAL, } \\
\text { Oxford }\end{array}$ & Hakan Ayral et. al.[14] & 2011 \\
\hline 10 & English & - & $\begin{array}{l}\text { Latent } \\
\text { Semantic } \\
\text { Indexing }\end{array}$ & TREC-8 & A N K Zaman et. al. [15] & 2011 \\
\hline 11 & English & - & Statistical & Dr Math & Laurie Butgereit et. al. [14] & 2011 \\
\hline 12 & Gujarati & 282 & Statistical & FIRE & Hardik Joshi et. al. [16] & 2012 \\
\hline 13 & Hindi & - & $\begin{array}{l}\text { Context } \\
\text { Window Size }\end{array}$ & Manually & Satyendr Singh et. al. [17] & 2012 \\
\hline 14 & Thai & - & TFIDF & $\begin{array}{l}\text { Primary } \\
\text { School } \\
\text { Books }\end{array}$ & $\begin{array}{l}\text { Patcharanut Daowadung et. al. } \\
{[18]}\end{array}$ & 2012 \\
\hline 15 & Hindi & - & $\begin{array}{l}\text { Deterministic } \\
\text { Finite } \\
\text { Automata }\end{array}$ & TREC & Vandana Jha et. al. [19] & 2016 \\
\hline 16 & Gujarati & - & Rule based & Manually & Rajnish M. Rakholia et. al. [20] & 2017 \\
\hline 17 & Gujarati & 206 & Manually & Manually & Chandrakant D. Patel [7] & 2017 \\
\hline
\end{tabular}


Towards Excellence: An Indexed, Refereed \& Peer Reviewed Journal of Higher Education / Mr.

Chandrakant Patel \& Dr. Jayeshkumar Patel / Page 594-607

\begin{tabular}{|l|l|l|l|l|l|l|}
\hline 18 & Gujarati & 473 & Rule based & Hybrid & Proposed & 2019 \\
\hline
\end{tabular}

Till now, there is no standardized, exhaustive and dynamic stop word list created for documents written in Indian Gujarati language which is spoken by nearly 66 million people worldwide [20].

\section{Our approach:}

We have used the rules-based approach to generate a dynamic stop list from the Gujarati language documents written in digital format and encoded in UTF-8. We have considered the length of the word to identify the stop list for that we need to define an algorithm to find the length. The Gujarati word written with Simple and Compound alphabets, including several diacritics. The punctuation marks which are indicate end of markers for the Gujarati statement. It is noteworthy to mention here that the length of that stop list found by hybrid rules which is influenced by the punctuation, diacritics and alphabetic list as well. To design and implement a length-dependent approach, we have deployed the usage of fact that each punctuation and diacritics mark with simple and compound alphabets in written Gujarati documents.

We mentioned and derived total 20 kinds of rules to identify general stop list from selected CIIL datasets and then apply these rules on other datasets to get and compare the effective output of these rules.

Some of the interesting facts about the Gujarati language stop list as per datasets:

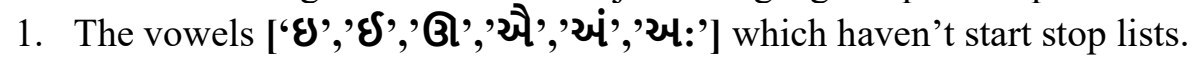

2. The consonants ['ઝ','ટ','S','ધ','ષ'] which haven't start with stop list.

3. There are no words as well as stop words that start with ['ણ', 'ળ'] consonants.

\section{General rules:}

Rule 0: All syllables do not appearing with [']'] (હલન્ત) diacritics sign.

Rule 1: The first syllable does not start with [‘'’] (અનુસ્વાર) diacritics sign.

Rule 2: All single syllable word with or without diacritics, were considered in stop list and remove, except only ['માં', 'યા', 'બા', 'ધી', 'પી', 'ગૌ', 'શ્રી', 'બે', 'સૌ', 'બી', 'સ્ત્રી', 'ડૉ', 'મૉં', 'મોં', 'જ્કી', 'ભા', 'ખા', 'ચ્હા', 'સ્વ', 'ફી'].

For Example: ['અ', 'આ', 'ઇ', 'એ', 'ઓ', 'કે', 'કે:', 'કો']

Rule 3: All double syllable word which follow Rule 1 on first syllable and last syllable must be from ['થી','ના'], were considered in stop list and remove.

For Example: ['ક્યાંથી', 'ત્યાંથી', 'ત્યાંના', 'માંથી']

Rule 4: All double syllable word which having ['એ','આl','ઈ','ક','ત'] and last syllable must be end with ['ની'], were considered in stop list and remove.

For Example: ['એ', 'ની'], ['તે', 'ની']

Rule 5: All double syllable word which start with ['अ'] in first syllable which follow Rule 1 and ['] (એક માત્ર) in second syllable and Rule 0, were considered in stop list and remove. For Example: ['અને', 'અમે'] 
Rule 6: All double syllable word which start with ['आl'] in first syllable and second syllable must be in ['જ','થ','ન','પ','મ','વ'] with or without diacritics sign and word does not contains ['''] with Rule 0, were considered in stop list and remove.

For Example: ['આ', 'જે'], ['આ', 'વ્યા'], ['આ', 'પ'], ['આ', 'માં']

Rule 7: All double syllable word which start with ['એ'] in first syllable and second syllable must be in ['ણ','ન','મ','વ'] with or without diacritics sign and Rule 0, were considered in stop list and remove.

For Example: ['એ', 'મા'], ['એ', 'માં'], ['એ', 'વા'], ['એ', 'ણે'], ['એ', 'ના']

Rule 8: All double syllable word which ends with ['ઇ',' $ઈ ']$ in second syllable and first syllable does not have any diacritics, were considered in stop list and remove.

For Example: ['ક', 'ઈ'], ['ગ', 'ઈ'], ['જ', 'ઈ'], ['થ', 'ઈ'], ['લ', 'ઈ']

Rule 9: In double syllables, the first syllable must be start with [' $₹$ '] which follows the Rule 0 and Rule 1, were considered in stop list and remove.

A. The second syllable must be from ['ય','2','s','શ'] but does not have any diacritic sign.

For Example: ['ક', 'યા'], ['ક', 'રી'], ['ક', 'રે'], ['ક', 'રો'], ['ક', 'શી'], ['ક', 'હી'], ['ક', 'હે'], ['ક', 'હો']

B. The first syllable end with ['’,','] diacritic sign and second syllable start with ['મ','વ','ન','ણ'].

For Example: ['કે', 'મ'], ['કે', 'વી'], ['કો', 'ણ'], ['કો', 'ને']

Rule 10: In double syllables, the first syllable must contains ['s'] not having [' ', 'ी',','] diacritic sign and second syllable must contain ['त'], were considered in stop list and remove. For Example: ['હ', 'તl'], ['હ', 'તiં'], ['હ', 'તી'], ['હ', 'તું'], ['હ', 'તો'], ['હો', 'ત'], ['હો', 'તiં'] Rule 11: In double syllables, the first syllable must contain [' $\gamma$ '] which follows Rule 0, were considered in stop list and remove.

A. The second syllable must be from ['त','व'] but first syllable does not have ['ी,', l'] diacritic sign.

For Example: ['જ', 'તો'], ['જ', 'વl'], ['જ', 'વું'], ['જ', 'વો'], ['જે', 'વl']

B. The first syllable end with [']'] diacritic sign and second syllable start with ['ણ','થ','ન','મ','વ'] with or without diacritics sign.

For Example: ['જે', 'ણે'], ['જે', 'થી'], ['જે', 'ના'], ['જે', 'નાં']

Rule 12: In double syllables, the first syllable must contain ['त'] without [']'] diacritic sign which follow Rule $\mathbf{0}$ and second syllable start with ['ણ','ન','મ','વ'] with or without diacritics sign, were considered in stop list and remove.

For Example: ['તે', 'ને'], ['તે', 'નો'], ['તે', 'મ'], ['તે', 'માં'], ['તે', 'વા']

Rule 13: In double syllables, the first syllable must contain ['થ'] which follows Rule 0 and Rule 1, additionally first and second syllable must be without diacritics sign, were considered in stop list and remove.

For Example: ['થ', 'તl'], ['થ', 'તી'], ['થ', 'યા'], ['થ', 'યો'], ['થ', 'વl'] 
Rule 14: In double syllables, the first syllable must contains ['મ'] having ['l'] diacritic sign and second syllable must contain [' 2 '] with diacritics sign which follows Rule 0, were considered in stop list and remove.

For Example: ['મા', 'રા'], ['મા', 'રાં'], ['મા', 'રી'], ['મા', 'રું'], ['મા', 'રે'], ['મા', 'રો'] Rule 15: In three syllables, the last two syllable must be end with from ["ઈએ","ઈશ","નાથી","વાથી","માંથી"]. The first syllable does not start with ['સ'] and without ['l','ґ','] diacritics sign were considered in stop list and remove.

For Example: ['આ', 'માં', 'થી'], ['એ', 'ના', 'થી'], ['જો', 'ઈ', 'એ'], ['તે', 'માં', 'થી'], ['લ', 'ઇ', 'ओ']

Rule 16: In three syllables, the last two syllables contain from ["જન", "પણ", "પત", "પન", "પશ", "પેલ", "મન", "વત"]. The first syllable must start with ['આ',એ'] and follow the Rule 0, were considered in stop list and remove.

For Example: ['આ', 'વ', 'તી'], ['એ', 'મ', 'નો'], ['આ', 'પ', 'શે'], ['આ', 'વ', 'તાં']

Rule 17: In three syllables, the last two syllables contain from ["કત","કય","કશ"]. The first syllable must start with ['2','s'] with or without diacritic sign and follow the Rule 0, were considered in stop list and remove.

For Example: ['શ', 'ક', 'તl'], ['શ', 'ક', 'તાં'], ['શ', 'ક', 'ય'], ['શ', 'ક', 'યો'], ['શ', 'ક', 'શું'] Rule 18: In three syllables, the last two syllables contain from ["રત","૨વ","રશ","રન","હેત","હેલ","હેવ"]. The first syllable must start with ['ક','ર'] without diacritic sign and second syllable does not have ['],',',']'] diacritic sign and follow the Rule 0, were considered in stop list and remove.

For Example: ['ક', '૨', 'વા'], ['ક', '૨', 'શે:'], ['૨', 'હે', 'તું'], ['૨', 'હે', 'લો'], ['૨', 'હે', 'વા']

Rule 19: In three syllables, the last two syllables contain from ["મન","માર"]. The first syllable must start with ['त'] without diacritic sign and follow the Rule 0, were considered in stop list and remove.

For Example: ['ત', 'મ', 'ને'], ['તે', 'મ', 'ના']. ['તે', 'મ', 'નાં'], ['તે', 'મ', 'ની'], ['તે', 'મ', 'નું'] Rule 20: In three syllables, the last two syllables contain from ["તાન","નત","નશ"]. The

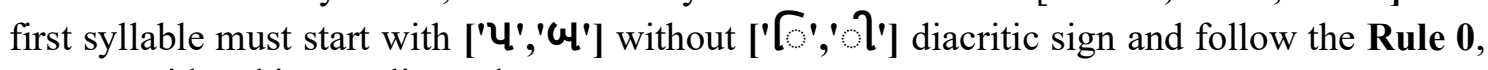
were considered in stop list and remove.

For Example: ['પો', 'તl', 'ને'], ['પો', 'તl', 'નો'], ['બ', 'ન', 'તુ'], ['બ', 'ન', 'તું'], ['બ', 'ન', 'शे']

\section{Datasets with TTR statistics:}

The corpora were hybrid which was collected randomly from websites and standard collection from EMILLE group, to avoid the bias of the single corpus on proposed work. For experimental purpose, we were considered following [Table 2] statistics of our corpora.

Tokenization is that the method of given running raw text (electronic text) into sentences then into tokens. The nature of tokenization varies language to language; it depends on the kind of languages, their structures, writing systems and the structure of the words. In NLP, excluding different usages, the output of tokenizer primarily used as associate input of stemmer, morph instrument, lemmatizer and components of speech tagger.

Segmentation is not only to splits words but it may consider with punctuation marks or other symbols that depends on the usage of the tokens for the particular application. The tokens can be words, numbers or punctuation marks. So, we need to decide boundary for tokens while 
Towards Excellence: An Indexed, Refereed \& Peer Reviewed Journal of Higher Education / Mr.

Chandrakant Patel \& Dr. Jayeshkumar Patel / Page 594-607

creating tokenization process. A word type is the form or spell of word that represent unique word of vocabulary. To calculate the new word ratio or lexical richness of the datasets that is called as Token Type Ratio (TTR). The TTR also renamed as lexical diversity. So, through these statistics, $50 \%$ words were not unique which need to stemming or lemmatization after stop list words removed from this corpus.

$$
\text { TTR }=\frac{\text { Total of Tokens }}{\text { Total of Types }}
$$

Equation 1 Lexical Diversity

or TTR

Table 2 Statistics of Corpora

\begin{tabular}{|l|r|r|r|r|r|}
\hline Name of Datasets & $\begin{array}{l}\text { Total of } \\
\text { File } \\
\text { Name }\end{array}$ & $\begin{array}{l}\text { Total of } \\
\text { Lines }\end{array}$ & $\begin{array}{l}\text { Total of } \\
\text { Tokens }\end{array}$ & $\begin{array}{l}\text { Total of } \\
\text { Types }\end{array}$ & $\begin{array}{l}\text { Average of } \\
\text { TTR }\end{array}$ \\
\hline CIIL & 3 & 629 & 8728 & 4183 & 49.08 \\
\hline EDUCATION & 8 & 1487 & 30001 & 8467 & 36.25 \\
\hline HEALTH & 21 & 1814 & 33985 & 14251 & 45.95 \\
\hline LEGAL & 8 & 838 & 20250 & 7052 & 37.84 \\
\hline NEWS & 136 & 39420 & 737872 & 346997 & 47.40 \\
\hline NEWS-GEN & 38 & 28892 & 444448 & 174520 & 41.51 \\
\hline NEWS-NAT & 235 & 35199 & 761869 & 382797 & 51.23 \\
\hline NEWS-REG & 216 & 193841 & 4022661 & 1391596 & 34.92 \\
\hline SUPP & 280 & 322425 & 4808287 & 1741986 & 37.86 \\
\hline $\begin{array}{l}\text { GUJARATI } \\
\text { STORY }\end{array}$ & 52 & 8139 & 95392 & 49235 & 54.10 \\
\hline Grand Total & $\mathbf{9 9 7}$ & $\mathbf{6 3 2 6 8 4}$ & $\mathbf{1 0 9 6 3 4 9 3}$ & $\mathbf{4 1 2 1 0 8 4}$ & $\mathbf{4 2 . 8 5}$ \\
\hline
\end{tabular}

\section{Implementation on Datasets:}

The dynamic stop list algorithm using rules based approach implemented in Python. The python language supports UTF-8 encoding format, default. The random selection taken for implementation and testing from collected datasets.

We tested our result using word cloud and compare it manually with linguistic expert of the Gujarati language with different five testing cases. We got few results which wrongly accept by our rules and we need to improve. The accuracy of the stop list considered based on [Equation 2 Accuracy of Stop List] and result display in [Table 3]

$$
\begin{aligned}
& \text { Accuracy } \\
& =\frac{\text { No. of Stop List }- \text { No. of incorrect Stop List } * 100}{\text { No. of Stop List }}
\end{aligned}
$$

Equation 2 Accuracy of Stop

List

Table 3 Comparison of Stop List words accuracy for datasets

\begin{tabular}{|l|c|c|c|c|}
\hline No. & Datasets & No. of & No. of incorrect Stop list & Accuracy \\
\hline
\end{tabular}


Towards Excellence: An Indexed, Refereed \& Peer Reviewed Journal of Higher Education / Mr.

Chandrakant Patel \& Dr. Jayeshkumar Patel / Page 594-607

\begin{tabular}{|c|l|c|c|c|c|r|}
\hline & \multicolumn{1}{|c|}{ Name } & Stop list & Length-01 & Length-02 & Length-03 & \\
\hline 1 & CIIL & 252 & 0 & 0 & 0 & $\mathbf{1 0 0 . 0 0 \%}$ \\
\hline 2 & EDUCATION & 307 & 0 & 0 & 0 & $\mathbf{1 0 0 . 0 0 \%}$ \\
\hline 3 & LEGAL & 270 & 0 & 0 & 0 & $\mathbf{1 0 0 . 0 0 \%}$ \\
\hline 4 & HEALTH & 349 & 0 & 0 & 0 & $\mathbf{1 0 0 . 0 0 \%}$ \\
\hline 5 & STORY & 486 & 0 & 2 & 0 & $\mathbf{9 9 . 5 8 \%}$ \\
\hline \multicolumn{2}{|c|}{ Average Stop list: } & $\mathbf{3 3 2 . 8}$ & \multicolumn{5}{|c|}{ Average Accuracy: } & $\mathbf{9 9 . 9 2 \%}$ \\
\hline
\end{tabular}

\section{Conclusion \& Future scope:}

Stop list gives us very effective result while stemming, web page categorization and text mining related applications. There are no any automatic tool to verified the stop list which generated by our proposed rules based approach for the Gujarati language. It is need to generate general stop list for Indian language which are derived from same hierarchy based on mapping techniques.

Table 4 Comparison of rule based approach

\begin{tabular}{|c|c|c|}
\hline $\begin{array}{l}\text { Rule } \\
\text { No. }\end{array}$ & Rule based approach [20] & Proposed Rule based Approach \\
\hline 1 & Exception list is limited. & $\begin{array}{l}\text { Enlarge the exception list. } \\
\text { For Example: ['શ્રી', 'બે', 'સૌ', 'મા', 'પી', 'બી', 'સ્ત્રી', } \\
\text { 'બા', 'ડૉ', 'મૉં', 'મોં', 'ગૌ', 'ક્ષી', 'ભા', 'ખા', 'પ્હા', 'સ્વ', } \\
\text { 'ચા', 'ધી', 'ફી'] }\end{array}$ \\
\hline 2 & $\begin{array}{l}\text { These words are not considered as stop } \\
\text { words with length is three which are } \\
\text { ending with 'થી'. } \\
\text { For Example: ['યો', 'ખા', 'થી'], ['સો', } \\
\text { 'ના', 'થી'] }\end{array}$ & $\begin{array}{l}\text { The same rule is very effective when last two syllable } \\
\text { contain ['ઈએ', 'ઈશ', 'નાથી', 'વાથી', 'માંથી'] and first } \\
\text { syllable does not start with ['સ'] and without these } \\
\text { [',',',']'] diacritic sign. } \\
\text { For Example: ['આ', 'ના', 'થી'], ['આ', 'માં', 'થી'], } \\
\text { ['એ', 'ના', 'થી'], ['એ', 'માં', 'થી'], ['કાં', 'ઈ', 'એ'], } \\
\text { ['કી', 'ઇ', 'એ'] }\end{array}$ \\
\hline 2 & $\begin{array}{l}\text { These words are not considered as stop } \\
\text { words with length is two which are } \\
\text { ending with 'थी'. }\end{array}$ & $\begin{array}{l}\text { The same rule is very effective with but first syllable } \\
\text { must have ['ं'] diacritics sign. } \\
\text { For Example: ['ક્યાં', 'થી'], ['જ્યાં', 'થી'], ['જ્યાં', }\end{array}$ \\
\hline
\end{tabular}




\begin{tabular}{|c|c|c|}
\hline & $\begin{array}{l}\text { For Example: ['ધી', 'થી'], ['સા', 'થી'], } \\
\text { ['સ્ત્રી', 'થી'], ['હા', 'થી'] }\end{array}$ & 'ના'], ['ત્યાં', 'થી'], ['ત્યાં', 'ના'], ['માં', 'થી'] \\
\hline 3 & $\begin{array}{l}\text { These words are not considered as stop } \\
\text { words with length is two which ending } \\
\text { with 'વો' } \\
\text { For Example:['કૂ', 'વો'], ['ખા', 'વો'], } \\
\text { ['ટે', 'વો']['દl', 'વો'], ['દી', 'વો'], ['બા', } \\
\text { 'વો'] }\end{array}$ & 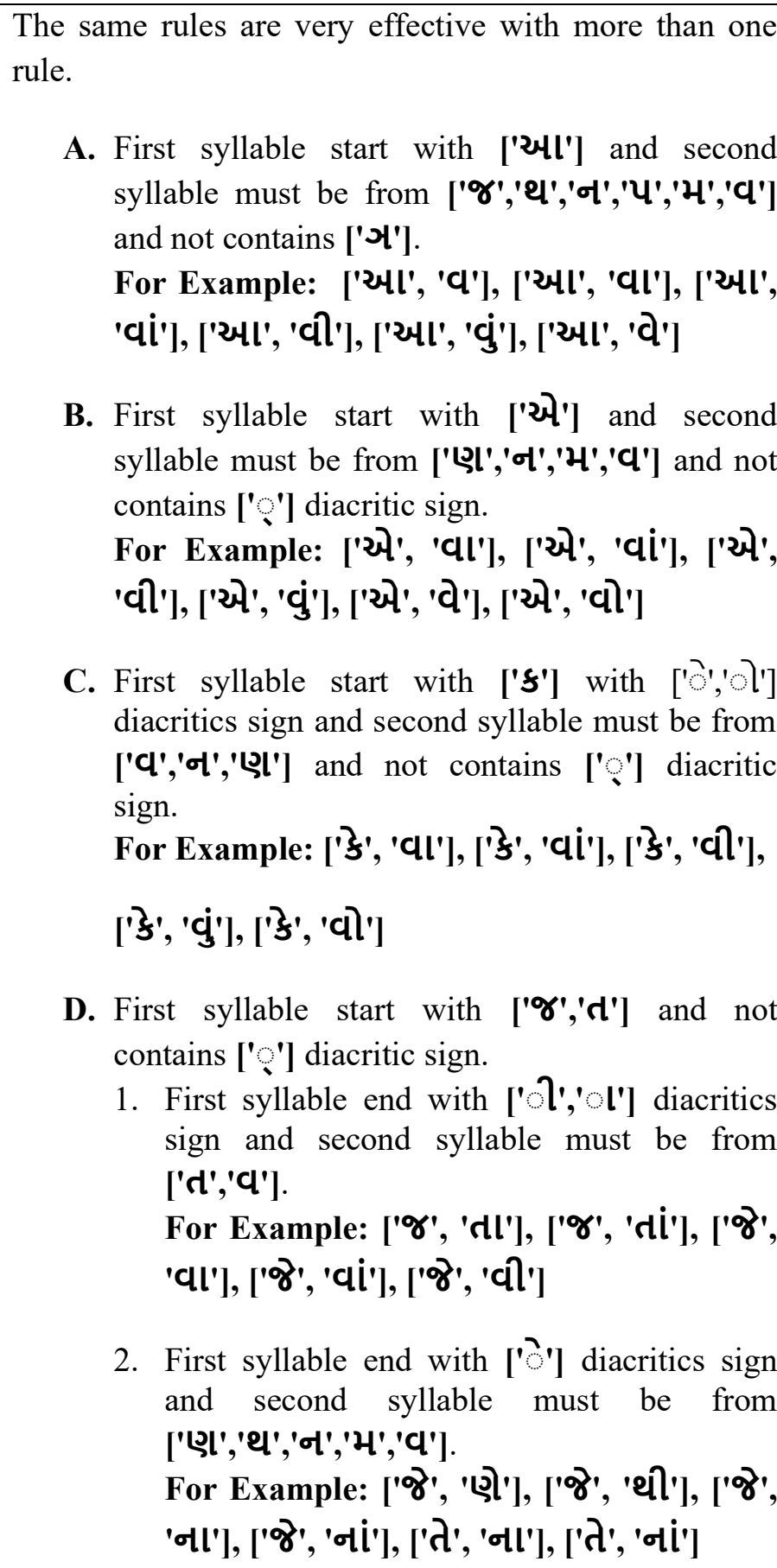 \\
\hline 4 & $\begin{array}{l}\text { These words are not considered as stop } \\
\text { words with length is two which are } \\
\text { ending with 'नी'. }\end{array}$ & $\begin{array}{l}\text { The same rule is very effective with but first syllable } \\
\text { must have ['એ','આ','£','ধ','ત'] and second syllable } \\
\text { must be end with ['ની']. }\end{array}$ \\
\hline
\end{tabular}




\begin{tabular}{|c|c|c|}
\hline & $\begin{array}{l}\text { For Example: ['ખૂ', 'ની'], ['જૂ', 'ની'], } \\
\text { ['ધू', 'ની'] }\end{array}$ & $\begin{array}{l}\text { For Example: ['આ', 'ની'], ['ઈ', 'ની'], ['ઈ', 'ની'], } \\
\text { ['એ', 'ની'], ['કે', 'ની'], ['કી', 'ની'], ['તે', 'ની'], }\end{array}$ \\
\hline 5 & $\begin{array}{l}\text { These words are not considered as stop } \\
\text { words with length is two which are } \\
\text { ending with 'ણ'. } \\
\text { For Example: ['ખू', 'ણો'], ['છી', 'ણી'], } \\
\text { ['ઝી', 'ણી'], ['દl', 'ણા'], ['મ', 'ણિ'] }\end{array}$ & $\begin{array}{l}\text { The same rule is incorporate with above rules. } \\
\text { For Example: ['જે', 'ણે'], ['કો', 'ણે'], ['એ', 'ણે'] }\end{array}$ \\
\hline 6 & $\begin{array}{l}\text { These words are not considered as stop } \\
\text { words with length is two which are } \\
\text { ending with 'नु' } \\
\text { For Example: ['घे', 'નु'], ['मे', 'નु'] }\end{array}$ & $\begin{array}{l}\text { The same rule is incorporate with above rules. } \\
\text { For Example: ['જે', 'નु'], ['એ', 'નુ'] }\end{array}$ \\
\hline 7 & $\begin{array}{l}\text { These words are not considered as stop } \\
\text { words with length is two which are } \\
\text { ending with 'ઇ'. } \\
\text { For Example: ['ખા', 'ઇ'], ['ગા', 'ઇ'], } \\
\text { ['જो', 'ઇ'], ['સू', 'ઇ'] }\end{array}$ & 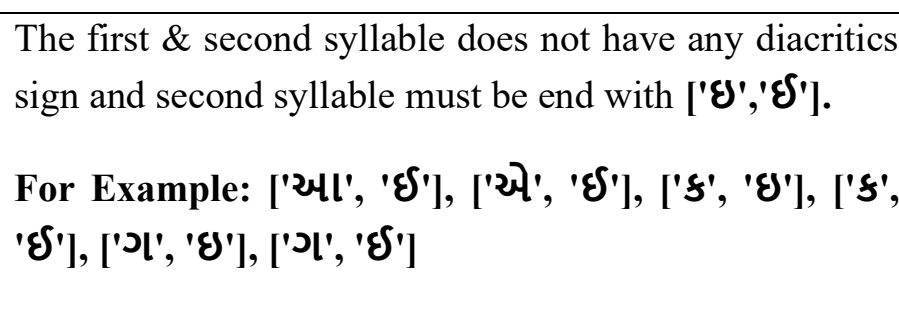 \\
\hline 8 & 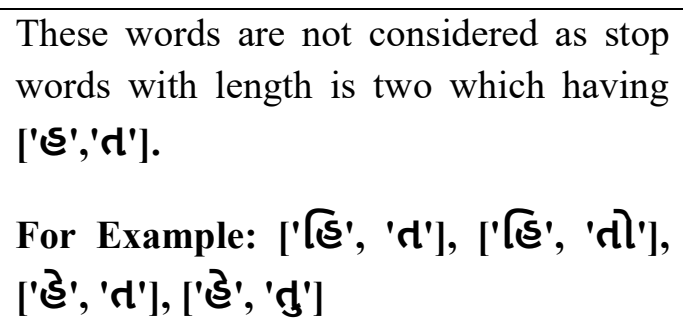 & 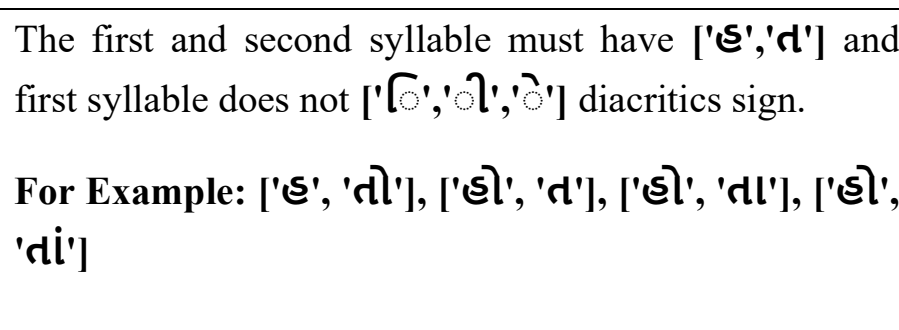 \\
\hline 9 & $\begin{array}{l}\text { These words are not considered as stop } \\
\text { words with length is two which end with } \\
\text { ['Aે']. } \\
\text { For Example: ['યા', 'ને'], ['સ્કૂ', 'ને'], } \\
\text { ['સ્ત્રી', 'ને'], ['સ્થl', 'ને'] }\end{array}$ & $\begin{array}{l}\text { The words does not contains ['] diacritic sign and } \\
\text { incorporate with above rules. } \\
\text { For Example: ['આ', 'ને'], ['એ', 'ને'], ['જે', 'ને'] }\end{array}$ \\
\hline 10 & $\begin{array}{l}\text { These words are not considered as stop } \\
\text { words with length is two which end with } \\
\text { ['મ']. } \\
\text { For Example: ['પ્ર્', 'મ'], ['બू', 'મ'], } \\
\text { ['સू', 'ક્ષ્મ'] }\end{array}$ & $\begin{array}{l}\text { The first syllable which start with ['ત','એ','જ'] and } \\
\text { second syllable must be contain ['ણ','ન','મ','વ'] with } \\
\text { word does not contains ['९'] diacritic sign. } \\
\text { For Example: ['આ', 'મ'], ['આ', 'માં'], ['એ', 'મ'], } \\
\text { ['એ', 'માં'], ['જે', 'મ'], ['તે', 'મ'] }\end{array}$ \\
\hline
\end{tabular}




\begin{tabular}{|c|c|c|}
\hline 11 & $\begin{array}{l}\text { These words are not considered as stop } \\
\text { words with length is two which end with } \\
\text { ['તો','ત']']. } \\
\text { For Example: ['ખા', 'તી'], ['ગા', 'તી'], } \\
\text { ['ગી', 'તો'], ['રા', 'તે'], ['રી', 'તો'], ['સં', } \\
\text { 'તો'] }\end{array}$ & $\begin{array}{l}\text { The same rule is incorporate with above rules. } \\
\text { For Example: ['હ', 'તો'], ['હો', 'તો'], ['જો', 'તો'], } \\
\text { ['જે', 'તે'] }\end{array}$ \\
\hline 11 & $\begin{array}{l}\text { These words are not considered as stop } \\
\text { words with length is three which end } \\
\text { with ['તી','ત']. } \\
\text { For Example: ['હ', 'સ', 'તે'], ['હ', 'સ', } \\
\text { 'તો'], ['પી', 'ડા', 'તો'], ['ધ્રૂ', 'જ', 'તી'] }\end{array}$ & $\begin{array}{l}\text { The first syllable start with ['આ',એ'] and second \& } \\
\text { third syllable contains ["જન", "પણ", "પત", "પન", } \\
\text { "પશ", "પેલ", "મન", "વત"] with word does not } \\
\text { contains ['્'] diacritic sign. } \\
\text { For Example: ['આ', 'વ', 'તે'], ['આ', 'વ', 'તી'], ['આ', } \\
\text { 'પ', 'તો'] }\end{array}$ \\
\hline
\end{tabular}

After implementing the rule based approach of [20], we found some limitation even the length given by them which matched due to datasets but we need to revised rules and we added new rules which more effective to collect the stop list compared to existing rule based approach. The comparison of rule based approach and proposed rule based approach are given [Table 4] with optimized stop list of Gujarati language.

\section{Compliance with Ethical Standards:}

Conflict of Interest: The authors declare that they have no conflict of interest. 
Towards Excellence: An Indexed, Refereed \& Peer Reviewed Journal of Higher Education / Mr.

Chandrakant Patel \& Dr. Jayeshkumar Patel / Page 594-607

\section{Bibliography}

C. D. Patel and T. Modi, "A mode of web page categorization of Gujarati language," Journal Of Information, Knowledge And Research In Computer Science And Applications, vol. 4, no. 1, pp. 200-203, 2015.

C. D. Patel and J. M. Patel, "Improving a Lightweight Stemmer for Gujarati Language," International Journal of Information Sciences and Techniques, vol. 6, no. 1, pp. 135$142,2016$.

R. Nallapati, J. Allan, and S. Mahadevan, "Extraction of Key Words from News Stories," CIIR Technical Report, vol. IR-345, pp. 1-6, 1993.

T. K. H. T. K. Ho, "Fast identification of stop words for font learning and keyword lnspotting," Proceedings of the Fifth International Conference on Document Analysis and Recognition. ICDAR '99 (Cat. No.PR00318), 1999.

Z. Yao and C. Ze-Wen, "Research on the construction and filter method of stop-word list in text preprocessing," Proceedings - 4th International Conference on Intelligent Computation Technology and Automation, ICICTA 2011, vol. 1, pp. 217-221, 2011.

W. J. Wilbur and K. Sirotkin, "The automatic identification of stop words," Journal of Information Science, vol. 18, no. 1. pp. 45-55, 1992.

C. D. Patel and J. M. Patel, "GUJSTER: a Rule based stemmer using Dictionary Approach," IEEE - International Conference on Inventive Communication and Computational Technologies (ICICCT 2017) GUJSTER:, no. IEEE, pp. 496-499, 2017.

C. D. Patel and J. M. Patel, "A Review of Indian and Non-Indian Stemming: A focus on Gujarati Stemming Algorithms," International Journal of Advanced Research, vol. 3, no. 12, pp. 1701-1706, 2015.

Z. Gong and G. Guan, "The selection of Mongolian stop words," Proceedings - 2010 IEEE International Conference on Intelligent Computing and Intelligent Systems, ICIS 2010, vol. 2, pp. 71-74, 2010.

L. Hao and L. Hao, "Automatic identification of stop words in chinese text classification," Proceedings - International Conference on Computer Science and Software Engineering, CSSE 2008, vol. 1, pp. 718-722, 2008.

C. Silva and B. Ribeiro, "The importance of stop word removal on recall values in text categorization," Proceedings of the International Joint Conference on Neural Networks, 2003., vol. 3, pp. 1661-1666, 2003.

M. P. Sinka and D. W. Corne, "Towards modernised and Web-specific stoplists for Web document analysis," Proceedings - IEEE/WIC International Conference on Web Intelligence, WI 2003. pp. 396-402, 2003.

F. Zou, F. L. Wang, X. Deng, S. Han, and L. S. Wang, "Automatic Construction of Chinese Stop Word List," Proceedings of the 5th WSEAS International Conference on Applied Computer Science, vol. 2006, pp. 1010-1015, 2006.

H. Ayral and S. Yavuz, "An automated domain specific stop word generation method for natural language text classification," INISTA 2011 - 2011 International Symposium on INnovations in Intelligent SysTems and Applications, pp. 500-503, 2011.

A. N. K. Zaman, P. Matsakis, and C. Brown, "Evaluation of stop word lists in text retrieval using Latent Semantic Indexing," 2011 Sixth International Conference on Digital Information Management, pp. 133-136, 2011.

H. Joshi, J. Pareek, R. Patel, and K. Chauhan, "To stop or not to stop - Experiments on stopword elimination for information retrieval of Gujarati text documents," 3rd Nirma University International Conference on Engineering, NUiCONE 2012, pp. 6-8, 2012.

S. Singh and T. J. Siddiqui, "Evaluating effect of context window size, stemming and stop word removal on Hindi word sense disambiguation," Proceedings - 2012 
International Conference on Information Retrieval and Knowledge Management, CAMP'12, pp. 1-5, 2012.

P. Daowadung and Y. H. Chen, "Stop word in readability assessment of Thai text," Proceedings of the 12th IEEE International Conference on Advanced Learning Technologies, ICALT 2012, pp. 497-499, 2012.

V. Jha, N. Manjunath, P. D. Shenoy, and K. R. Venugopal, "HSRA: Hindi stopword removal algorithm," International Conference on Microelectronics, Computing and Communication, MicroCom 2016, 2016.

R. M. Rakholia and J. R. Saini, "Rule based Approach to Identify Stop Words for Gujarati Language," Proceeding of the 5th International Conference on Frontiers in Intelligent Computing: Theory and Applications, Advances in Intelligent Systems and Computing, pp. 797-806, 2017.

\author{
Chandrakant D. Patel, \\ Research Scholar, Hemchandracharya North Gujarat University \\ cdpatel4phd@gmail.com \\ \& \\ Dr. Jayeshkumar M. Patel \\ Professor \\ Ganpat University - Acharya Motibhai Patel Institute of Computer Studies \\ , Kherwa \\ jayeshpatel mca@yahoo.com
}

